\title{
Art Museums and Galleries: Retrospective Repertoire of Imaginative Freedom
}

\author{
Gauri Arora* and Megha Purohit Attray
}

Banasthali University, India

\begin{abstract}
Art Museums and Galleries are wealth of imaginative freedom of the artists. The museums and galleries hold the mantle to repertoire traditional art for contemporary generations. While the artefacts displayed are product of freedom of dreams and beliefs, they were merely developed as a result of literary imagination. Museums and galleries facilitate the visitors by visual narratives of retrospective freedom and imagination; but are they effective in connecting the dots of history, imagination \& freedom with culture? This research question is articulated by case studies of Maharaja Sawai Man Singh II Museum and Indian Contemporary Art (ICA) Gallery at Jaipur, in Rajasthan state of India. For museums and galleries exhibit paintings, the purpose of the study is to identify how they fuel the imagination of visitors by the means of traditional \& cultural knowledge. This study conducts qualitative analysis amongst visitors at these two artistic venues to gather their perspectives of whether their visit justified completion of wheel of imaginative freedom from artists to visitors. The findings of the study revealed a significant role of museums and galleries in giving birth to imagination and gathering evidence of relativism.
\end{abstract}

Keywords: Museums, Art Galleries, Paintings, Imagination, Culture, Freedom

\section{Introduction}

Museums and Art Galleries have been serving as platforms of cultural engagement from centuries. They are a catalyst of imagination which create meaning and memories for visitors. The artefacts exhibited in these spaces of art collections are not merely meant for transition of knowledge but they are rather intended to evoke emotions of the visitors which apparently may or may not coincide with that of artists. To a greater extent, these art depositories are oriented towards revenue generation, they are not meant to pander economic instincts alone. Art spaces such as museums \& galleries have been chosen for research as the objects exhibited in these spaces are moved out of the circulation within the society. Therefore, allegorical significance of imagination $\&$ freedom of artists is then showcased by these art spaces. The traditional paintings in the museums popularize the objects, putting a sense of continuity within the imagination of artists, visitors and ancient traditional cultures. Hence, this study aims to probe a perplexing influence of freedom and imagination over each other. It also aims to contemplate the thoughts of visitors which perpetuates to gain inspiration from the art works displayed in plethora. Therefore, this research intends to examine how art galleries and museums harness the visitors with ethos of past and present freedom to express, giving them a vision for future imagination.

\section{Literature Review}

\section{Museums \& Galleries: Repertoire of Art}

The freedom of imagination fuels the intensity of emotions with which the artists create their art works. The feelings and emotions of artists come across the surface with freedom of imagination (Haeyen, Kleijberg, \& Hinz, 2017). This resonates the creative freedom of the artist who took the liberty to lay focus on the intricacy of the buildings and surrounding rather than representing the stereotype faces of people attending the King's court room. In context to culture, Louden (2017) alludes artists to produce culture which creates a transparency into the lives lived by artists, capturing the imaginative ideas in their work of art. Museums \& Galleries on the other 
hand inspire the audience to challenge their boundaries of imagination while building a creative community together. This perhaps is affirmed by Anderson (2006) as he believed that the likelihood of artists being fortunate to meet the fellow artists is less yet, communion in their minds is evident. These artistic institutions divulge richness as they deconstruct the configurations of reality \& culture by offering a fluid coupling of freedom \& imagination that stands between art pieces and visitors in the museum spaces (Amundsen, 2014).

The paper presents the integrated experience of visitors at ICA Gallery and Sawai Man Singh II Museum of Jaipur. Jaipur is a city with extravagant architectural importance, prominently developed by the ancestors and predecessors of Jaipur's throne. Rich in heritage and closely intertwined with culture \& traditions, the city has been full of artistic composure not only in the museums \& palaces of the city but also in the markets of the city. Sawai Man Singh II Museum and ICA Gallery have been chosen for the research as they are indulged with exquisite repertoire of artistic galore. Majorly, tourist visitors are coming from different regions to explore the beauty and creativity of artists poured in the artifacts which are exhibited above mentioned art spaces at Jaipur, India.

Egan (2007) from his 'A Very Short History of Imagination' seamlessly puts forth definition of imagination in context of art. He considers that within ancient traditions, imagination was not explicitly admired but it was rather viewed as rebellion against authenticity and divinity of nature. It is defined as the capacity of artists to think of possibilities which diligently becomes source of innovation with a common involvement of emotions and thoughts (Bedford, 2014). The artistic imagination resonates with some concrete objects and ideas, free from the logical judgments. The opportunities given to artists for imagination are free from strategies or choices, enabling to think beyond the contingent thought of freedom without rules. Often, the artists demonstrate ambivalence towards the taught methods and rather follow their innate abilities to create art. Therefore, artists are often witnessed to resent the development in science and technology as it might influence the imaginative freedom of the artists (Coeckelbergh, 2017).

When the visitors arrive at art exhibition centers, they see historic artefacts as universal and infallible, experience of which is driven by their ideologies and expectations. Museums are a showcase of ideologies beheld in the past (Muller, 2013). At these exhibition halls, the visitors share a space but their mindsets are discreet. While the artistic imagination that is captured from their work of art is not envisaged through theoretical aspects, the area is of explicitly capable for detailed analysis \& investigation (Meeson, 1975). Hence, research is prone to involve expressive structures of freedom and imagination that are likely to form within the artists as well as visitors of museums \& art galleries.

\section{Method}

The study is aimed to examine the repertoire of Paintings at museums and galleries which have impact on the imaginative freedom. For the study, qualitative research has been proposed, with the researcher being independent from the subject under research. This method is adopted in art-oriented research as involvement, subjectivity and reflexivity is addressed. Conventional approach of qualitative approach with datasets formed from the interview transcripts have been gathered to capture distinct reflective thoughts (Bell, 2016).

\section{Data Collection}

The data has been collected by convenience sampling. For the data collection, visitors who visited the ICA Gallery and Maharaja Sawai Man Singh II Museum from the date of $1^{\text {st }}$ August 2020 to $31^{\text {st }}$ August 2020 were approached. Due to the recent Covid-19 outbreak, lesser number of visitors were witnessed at these art places. In order to conduct interview, the visitors were approached through a telephonic conversation to avoid the threat of infection. Open ended questions were asked to the participants, mentioned in Appendix. The open-ended conversations helped in finding patterns \& perspectives in imaginative freedom of visitors while embracing their 
contradictions with that of artists' imaginative freedom. Their general purpose of visit and inclination towards history and art provoked to further questions such as: What kind of thoughts come up on their visits? Does it fuel your imaginative ideas? Do the artists of previous times had greater imaginative freedom? Which art work amused you the most on your visit here?

\section{Data Analysis}

A systematic thematic approach has been followed for the research as it allows binding of conceptualized imagination of participants emerging from the art of separate period. However, it is not restricted to scientific research paradigms. The main focus of the themes is a discussion over contexts of imaginative freedom of the visitors to the art museums and galleries. The process of thematic exploration, coding of themes was done under the segregation of open, axial and selective coding. Firstly, the responses from the interviews were analyzed and the selected information was coded as open coding. Herein, the information which was important $\&$ relevant to comprehend the primary aim of the study was placed under open coding for tentative understanding. Thereafter, the relationship between open codes were stipulated on the basis of connections amongst the codes. Once all the axial codes were encompassed, selective coding was done to analyze the information which aligns with the core concept of investigating retrospect of imaginative freedom of visitors of art museums \& galleries.

Table 1 Open Codes for Research

\begin{tabular}{|c|c|c|}
\hline Open Codes & Properties & Discussion \\
\hline $\begin{array}{l}\text { To explore } \\
\text { View } \\
\text { Vacation } \\
\text { History }\end{array}$ & $\begin{array}{l}\text { Professional } \\
\text { Difference } \\
\text { Purposes } \\
\text { Creativity } \\
\text { Affinity for art } \\
\text { Curiosity to learn } \\
\text { about history }\end{array}$ & $\begin{array}{l}\text { The participants narrate } \\
\text { how elated they feel, } \\
\text { developing a connection } \\
\text { with art \& history as they } \\
\text { visit museums for different } \\
\text { purposes }\end{array}$ \\
\hline $\begin{array}{l}\text { Imagination } \\
\text { State of Mind } \\
\text { Ancient } \\
\text { Freedom of Expression } \\
\text { Independent Point of View } \\
\text { Inner Thoughts } \\
\text { Wild Ideas }\end{array}$ & $\begin{array}{l}\text { Accumulation of } \\
\text { Intensity } \\
\text { Synchronization } \\
\text { Appreciation for } \\
\text { novelty } \\
\text { Concerns over } \\
\text { freedom } \\
\text { Ascertaining new } \\
\text { perspectives }\end{array}$ & $\begin{array}{l}\text { There are common yet } \\
\text { distinct responses which } \\
\text { associate with novelty and } \\
\text { visitors come across during } \\
\text { their museum \& gallery } \\
\text { visits }\end{array}$ \\
\hline $\begin{array}{l}\text { Knowledge } \\
\text { Freedom } \\
\text { Culture } \\
\text { Traditions } \\
\text { Inspirations }\end{array}$ & $\begin{array}{l}\text { Freedom } \\
\text { Anticipation } \\
\text { Inheriting the ancient } \\
\text { ideologies } \\
\text { Bridging the gap } \\
\text { between Generations }\end{array}$ & $\begin{array}{l}\text { The freedom of imagination } \\
\text { for artists was central. } \\
\text { Museums \& Galleries } \\
\text { connect with the ancient } \\
\text { culture \& traditions }\end{array}$ \\
\hline
\end{tabular}


Table 2 Codes and Selective Codes for Research

\begin{tabular}{lll}
\hline Open Codes & Axial Codes & Selective Codes \\
\hline $\begin{array}{l}\text { Profession } \\
\text { Art Guseums }\end{array}$ & $\begin{array}{l}\text { Visits to Museums by } \\
\text { people belonging to } \\
\text { different professions }\end{array}$ & Difference in Imagination \\
$\begin{array}{l}\text { History } \\
\text { Interest \& Affinity towards Art }\end{array}$ & & \\
Curiosity & & \\
\hline Imagination & Freedom of & The veracity of freedom \\
State of Mind & Expression & and imagination in \\
Ancient & Closeness to Reality & Connection with Culture \\
Knowledge & Involvement in & \\
Freedom & correlation of & \\
Culture & contemporary thought & \\
& process with ancient & \\
\hline Traditions & history & Inspiration for Imaginative \\
Legacy of Visions of Artists & Anticipation & Freedom \\
\hline
\end{tabular}

\section{Discussion}

The relationship between art museums \& galleries with imaginative freedom has been critically analyzed and explored through the responses of participants from discrete aspects such as professions, purposes to visit the art places and thought process. The inquiry on museums $\&$ galleries being retrospective repertoires of imaginative freedom has been facilitated by technique of thematic exploration. The site visits, existing literature and journals would be inadequate to interrogate, amplify and exemplify the thoughts in comparison to that of raw data collected by the researcher (Kroll, 2008). Hence, dialectic approach was chosen for the research to remedy lack of rigor between the thoughts of visitors at museum \& gallery.

Three themes were identified regarding the expressions of freedom \& imagination of people indulging in museums and galleries would never be sufficient to measure the rigor of how the visitors and artists opine about the imaginative freedom. Three underlying themes have been identified from the study: (1) The difference in mindsets \& imagination due to Profession of Visitors (2) Expression of Imaginative Freedom by Artists is retrospect of their culture (3) Disparity of imaginative freedom amongst Visitors. The first theme concerns with the variation in imaginative abilities and extent of expression of freedom reflected by the visitors as they belong to distinct professions. This theme is intrinsically links the profession and culture of visitors with their creativity in imagination. The second theme shows that the artists' reflection of expression of freedom of the artists is seen in their arts, visualizing the unreachable boundaries in their mind and pouring their imagination on art pieces they create. The third theme depicts difference in the imaginative freedom of the visitors which are influenced by various attributes such as purpose of visiting museums, curiosity to gain knowledge, appreciation for creativity \& newness and inspirations they seek to gain from their visit.

\section{Theme 1: Difference in mindsets \& imagination due to profession of visitors}

The participants for the proposed research were from different professions; some where students, software engineer, research analyst, businessman, artist and marketing person. While there were a few commonalities in their purpose of visiting Maharaja Sawai Man Singh II museum and ICA Art Gallery which affirms with exploring the ancient \& historic ethnicities across the city of Jaipur, their expressions over freedom and connection with art varied. In the case of a painting exhibited at Maharaja Sawai Man Singh II Museum, the incomplete painting demonstrated higher excellence in the architectural background of the court scene rather 
than the people attending the court room. When these participants were confronted for their views of the unfinished Painting presented in figure 1, their responses differed highly. The students viewed them with a cultural point of view, the businessman viewed it with respect to the kingship and power held by the king. The research analyst spotted minute details of intricacies in buildings. However, the artist was impressed with the scene captured that can give a live time travel to the court scene that has live music going on. This clearly indicates the approach taken in the form of functional freedom of expression which is spread in different directions of imagination without a minimal possibility of coincidence. Even though the participants appreciated creativity of the artefacts presented in the museum and gallery, their point of view with which they saw and appreciated is indifferent.

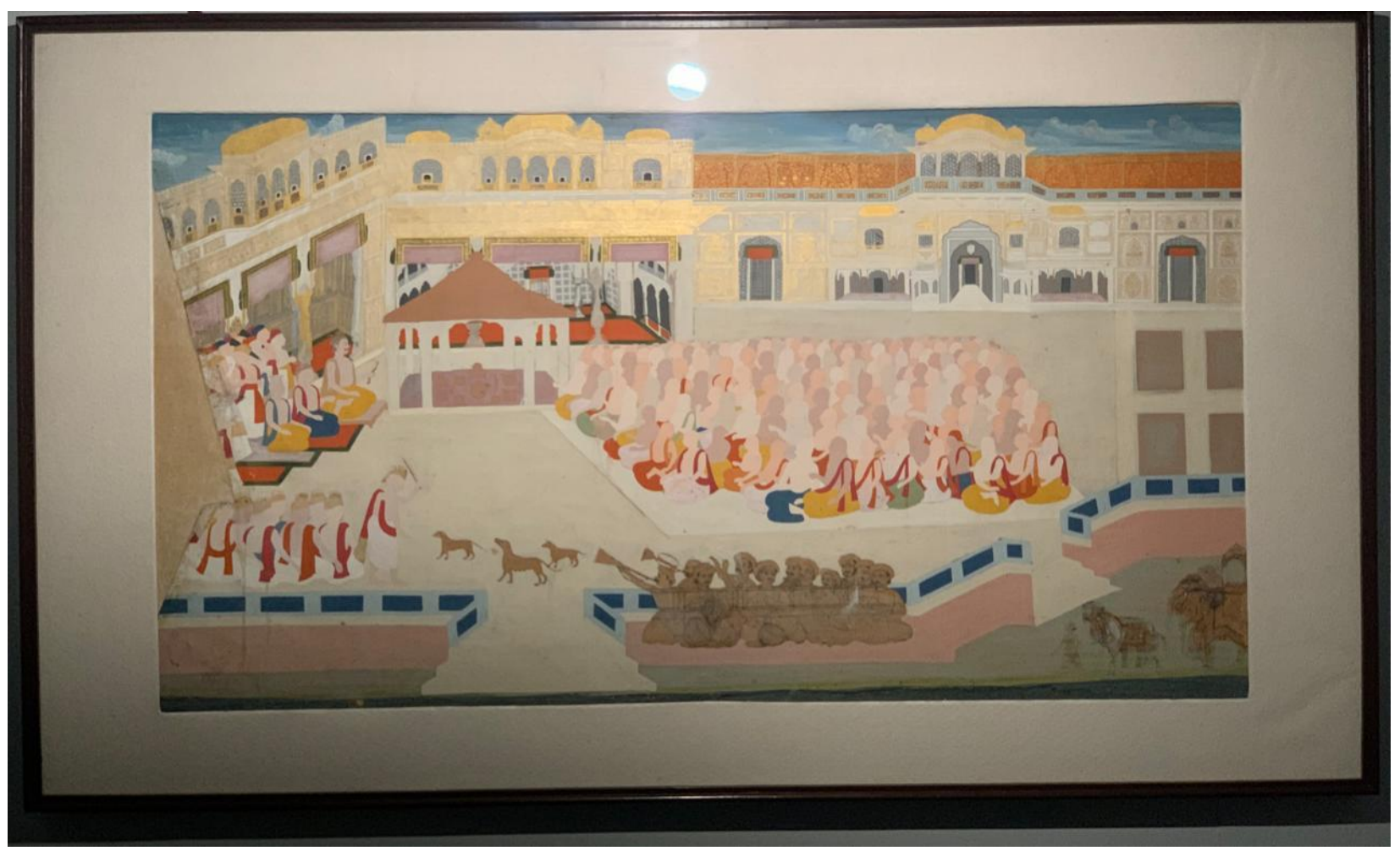

Figure 1: An Incomplete Court Scene wherein the Artist emphasizes on architectural background rather than people attending the Court, captured from Sawai Man Singh II Museum of Jaipur

\section{Theme 2: Expression of Imaginative Freedom by Artists is retrospect of their culture}

On realizing the freedom of expression in the art pieces, paintings \& sculptures created by the artists, it was found that the artists mainly relied on their surroundings and culture when they imagined. The freedom of imagination of the artists was authentic. However, paintings and sculptures from the ancient times as presented in figure 3, 4 and 5 reveal that their imagination was seized by the traditions, divinity and objects with which they had direct correlation at the time when the objects were made. For instance, as presented in figure 3, the Surya Chakra resonates the arms and ammunitions used in ancient India for wars. Figure 4 reflects the devotion and involvement of deities in the lifestyle of artists belonging from ancient India. Similar art has been craved and created in the doors (refer figure 5), replicating the imagination for a royal entrance. At the gallery, artists are present in order to educate the visitors about the culture and significance of art \& paintings exhibited inside. This insinuates that the artists pour ideas of their ancestors who created the art pieces, within the visitors to explain them the cultural traditions of ancient era. As the generation gap prevails, various objects presented in the museums are no longer in use as that of Surya Chakra in the form of arms \& ammunition. The artists, by giving a brief about the artifacts inculcate an imaginative freedom in the visitors by apprehension of their cultural correlation. 




Figure 2: Surya Chakra exhibited in Maharaja Sawai Man Singh II Museum of Jaipur depicts closeness of artists with their culture.

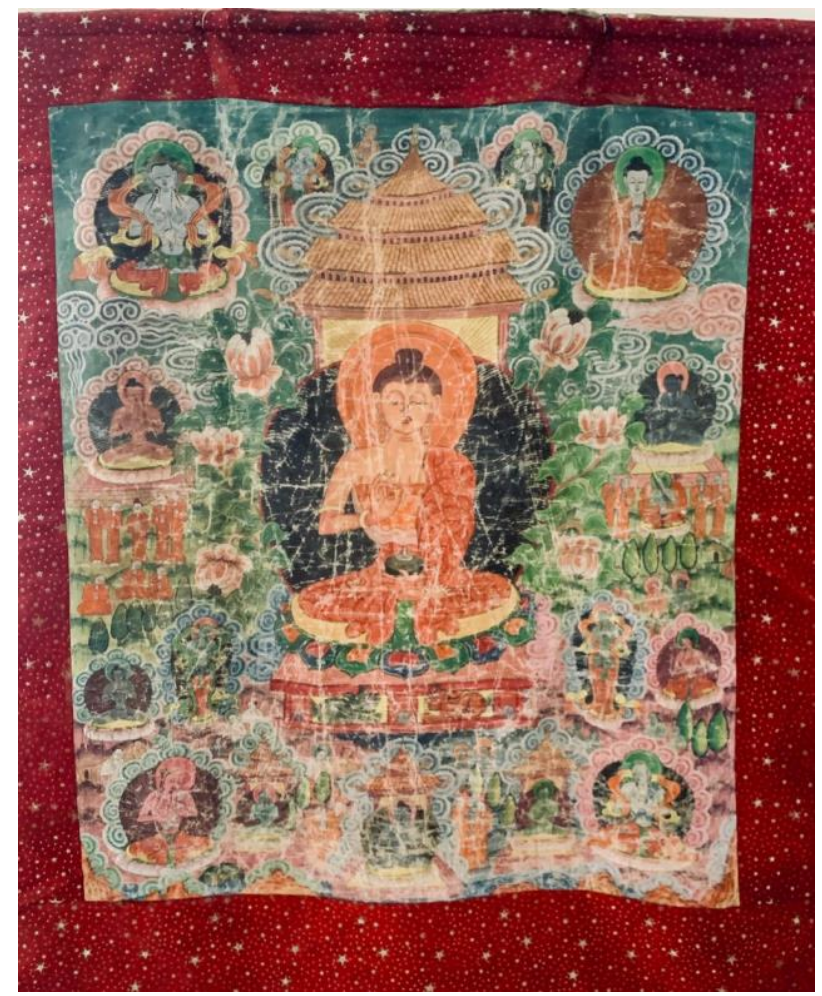

Figure 3: Surya Chakra exhibited in Maharaja Sawai Man Singh II Museum of Jaipur depicts closeness of artists with their culture. 




Figure 4: A piece of Gate wherein the cultural traditions of welcoming is intended by the Leela of Lord Krishna and Radha

\section{Theme 3: Gap in Imaginative Freedom of Traditional \& Contemporary Artists}

A subdued expression of emotions in the imaginative freedom of traditional artists can be witnessed in comparison to contemporary artists. As recorded from the responses, majority of them revealed that they are inspired by Indian folk Art such as Michelangelo's Vasudeo Kamath, Mughal Paintings or Shakuntala by Raja Ravi Verma. On the contrary, some respondents articulated their affinity towards modern art such as that of Vincent Van Gogh's Starry Night and Raqib Shaw's Imagined paradise; as shown in figure 6 and 7. These artefacts have uncanny wildness with which they are attributed to be bewildered. The imagination of contemporary artists is not constrained by boundaries. In figure 8 and 9 , the comparison of traditional \& modern imaginative freedom has been portrayed. Traditional paintings represent cultural ideologies combined with their creativity while modern artists ponder beyond stereotypical imagination without being incongruous in their work of art. This implies a gap in imaginative freedom within the generations that has emanated from the folks and cultures while promoting avant-garde in their art forms. 
Arora \& Attray/ Art Museums and Galleries: Retrospective Repertoire of Imaginative Freedom..

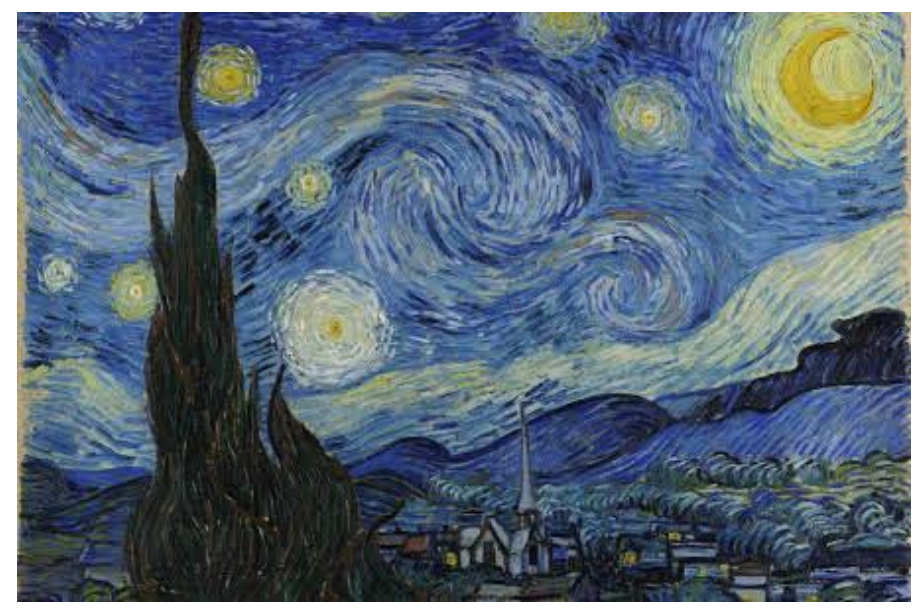

Figure 5: The famous painting 'The Starry Night' by Vincent Van Gogh portraying the view of dawn from his window with an imaginary village

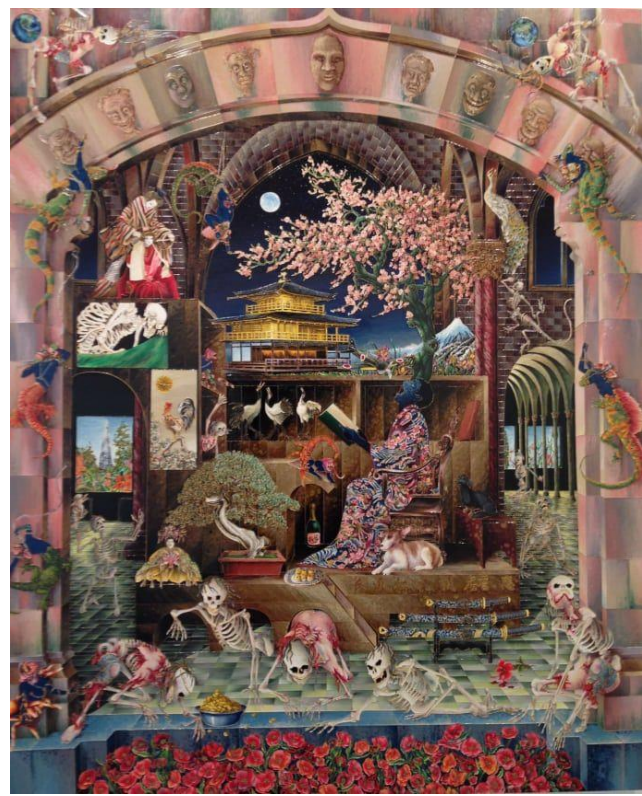

Figure 6: A Painting by Raqib Shaw representing imagined paradises, reflecting a freedom of imagination 


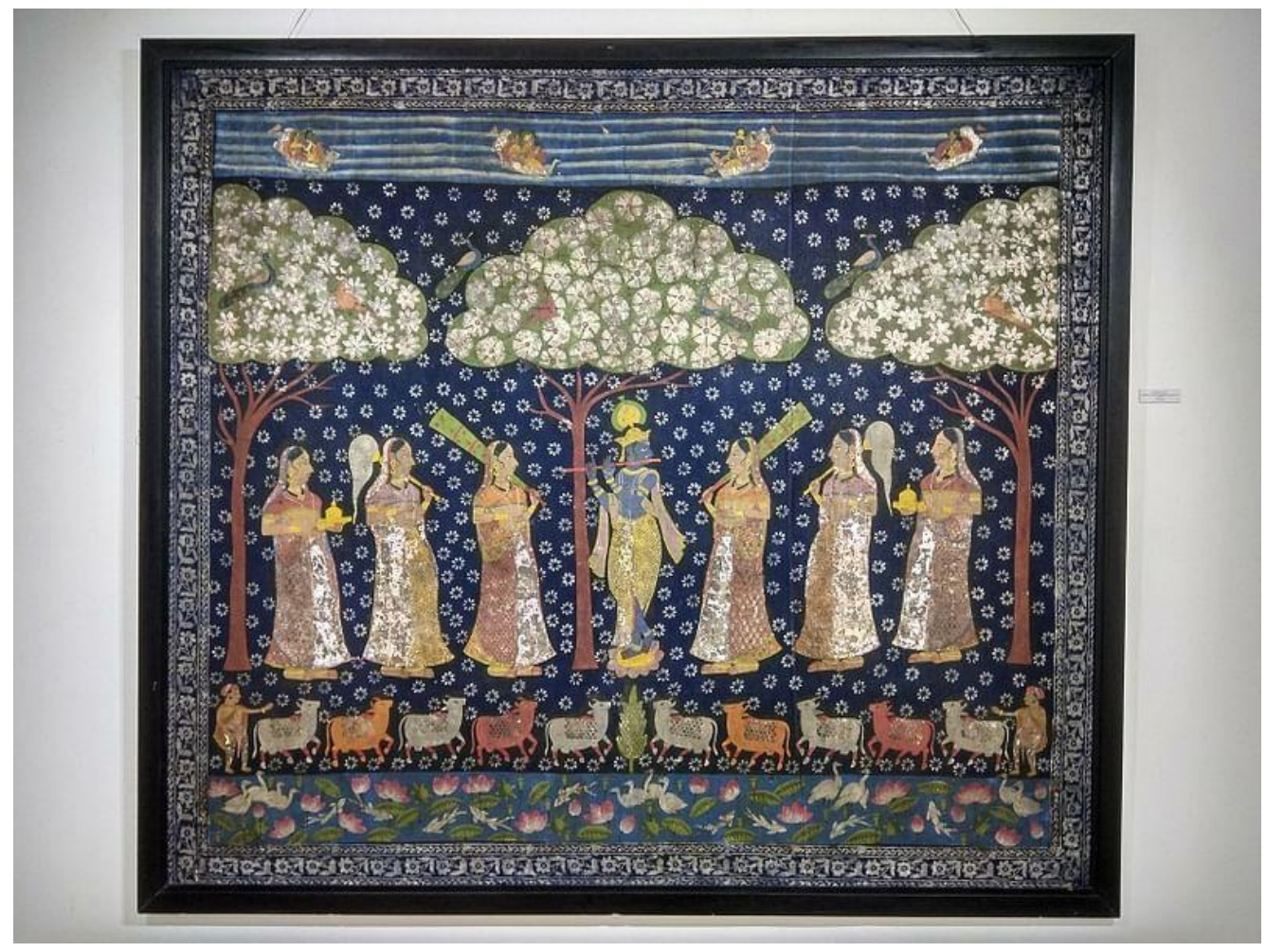

Figure 7: Pichwai Painting, a Traditional Form of Art in ICA Gallery representing indulgence of culture in their imagination

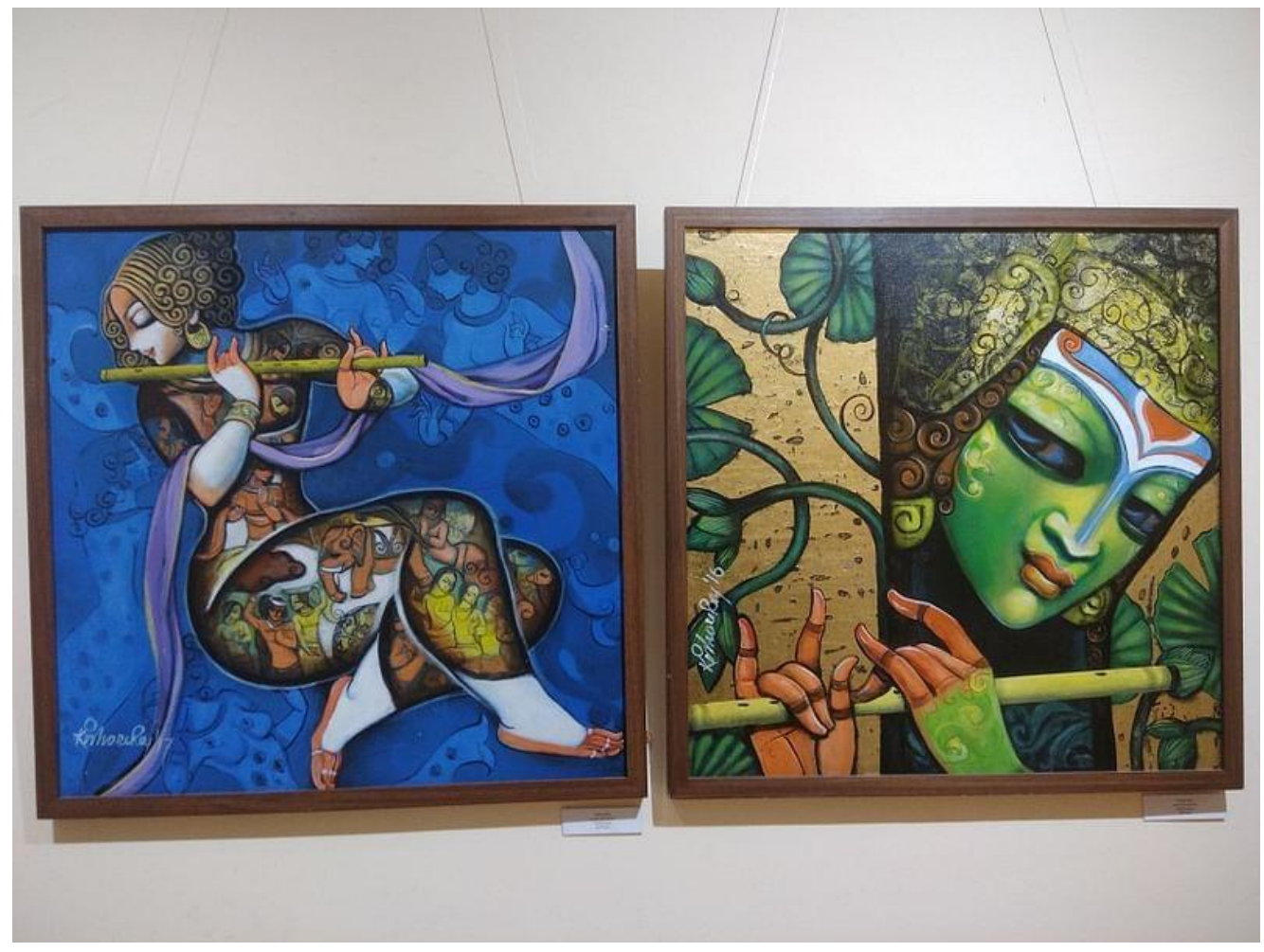

Figure 8: Contemporary Paintings at Art Galleries which represent Imaginative Freedom in Modern form of Art 


\section{Theme 4: Inspirations of Imagination \& Freedom}

From the interviews, several disparities in the imaginative freedom of the visitors can be witnessed. Apparently, this is due to several aspects which make their ideologies and mindsets distinct from each other. While the purpose of visiting museum and gallery of Jaipur varied, their expressions towards freedom in art work suggest that artists shape their imagination. They shared their thoughts about the freedom expressed by artists along with constraints of culture or laws due to which the artists curb their imagination. Respondents pinpointed that imagination was wider in the earlier eras, wherein the art works were not made. Eventually as the surroundings are filled with meant of unique and exquisite art creations, it is unlikely that the artists would not gain inspiration from the existing works. One of the respondents was artist herself, who along with other visitors agree that paintings from earlier times help the visitors to live the story woven by the imaginative freedom of artists, which could not be experienced if the paintings were not exhibited in the museums and galleries.

\section{Conclusion}

Museums and Gallery spaces are meant for creating renaissance of multifarious imagination \& freedom to express the imagination as they pay homage to the cultural past by addressing contested work of art. From the themes developed through thematic analysis, it can be observed that in earlier times, the customs of art were ossified with social \& cultural boundaries due to which, the freedom of imagination of the artists oscillated between a vilified zones. Over the generations, the freedom of imagination of artists appears to be celebrated as the art imagined \& created beyond the cultural boundaries is not judged but rather appreciated. Conducive to the responses from the interviews, the visitors have revealed that their imaginations, inspirations and ideologies are challenged and enhanced through their visits to art museums \& galleries. However, the freedom of imagination is the essence that deliberates their uptake against the profession, interests or emotions related to art. Thus, it can be concluded from the freedom expressed in the art work that the above mentioned art museum and gallery are a retrospect of imagination and freedom within art.

\section{Limitations}

In the present study, scope of research was limited to visitors who visited Maharaja Sawai Man Singh II and ICA Gallery of Jaipur from August $1^{\text {st }}$ to $31^{\text {st }}, 2020$. The research has engrossed opinions and mindsets of the participants through in-depth interviews. However, the research has not conducted quantitative research therefore, the significance, reliability \& validity of the study cannot be determined, subject to future research. The research encompasses opinions of visitors regarding the imagination \& freedom in correspondence to the museum \& gallery, however it lacks in engaging with the artists to reconnoiter their purview upon imaginative freedom. In future, there is a scope of research for these highlighted limitations to enhance generalization of the study stating that museums and galleries are retrospective repertoire of imagination $\&$ freedom.

\section{Acknowledgements}

I am grateful to present my deep regards to my mentor, parents and my friends who helped me focus on the study and showed me a pathway for accomplishing this research. I am thankful to everyone who lend a helping hand in completing my research.

\section{References}

Coeckelbergh, M. (2017). The art, poetics, and grammar of technological innovation as practice, process, and performance. AI \& SOCIETY, 33(4), pp.501-510.

Di Pietro, L., Guglielmetti Mugion, R., Renzi, M. and Toni, M. (2014). An Audience-Centric Approach for Museums Sustainability. Sustainability, 6(9), pp.5745-5762. 
Icon (2020). Conservation and care of collections during the Coronavirus pandemic. [online] icon.org.uk. Available at: https://icon.org.uk/news/conservation-and-care-of-collections-during-the-coronavirus-pandemic [Accessed 14 Aug. 2020].

Lord, B., Gail Dexter Lord and Martin, L. (2012). Manual of museum planning: sustainable space, facilities, and operations. Lanham, Md.: Altamira Press, C.

Lucchi, E. (2020). Environmental Risk Management for Museums in Historic Buildings through an Innovative Approach: A Case Study of the Pinacoteca di Brera in Milan (Italy). Sustainability, 12(12), p.5155.

National Museums (2008). NMDC guiding principles for reducing museums' carbon footprint. UK: National Museums Directors' Conference.

Pop, I., Borza, A., Buiga, A., Ighian, D. and Toader, R. (2019). Achieving Cultural Sustainability in Museums: A Step Toward Sustainable Development. Sustainability, 11(4), p.970. 
Arora \& Attray/ Art Museums and Galleries: Retrospective Repertoire of Imaginative Freedom..

\section{Appendix}

Questionnaire for Semi-structured Interviews

1. What are your thoughts when you enter the ICA or Maharaja Sawai Man Singh II Museum Museums?

2. What kind of thoughts do you get when you visit a historical art museum or art gallery?

3. Does a visit to museum fuel in new imaginative ideas in your mind regarding the ancient artefacts?

4. Do you like getting to know about the artists \& their culture while visiting museums?

5. Do you believe that artists had wide imagination earlier?

6. How likely do the artists express freedom through their art work?

7. Does a visiting museums or art galleries help you to know the traditional \& cultural knowledge?

8. Do you believe that history, freedom and imagination associated with art are interrelated?

9. How do art galleries and museums help you in connecting with imagination, freedom and culture of $\operatorname{art}$ ?

10. Is there any artist or any particular art work that has inspired you? 